\title{
Bone effects of hexarelin, a GH-releasing peptide, in female rats: influence of estrogen milieu
}

\author{
V Sibilia, D Cocchi ${ }^{1}$, I Villa ${ }^{2}$, N Lattuada, A Soglian, A Rubinacci ${ }^{2}$, E E Muller, A Pecile and C Netti \\ Department of Pharmacology, Chemotherapy and Medical Toxicology, University of Milan, Via Vanvitelli 32-20129 Milan, Italy, ${ }^{1}$ Department of \\ Biomedical Sciences and Biotechnology, University of Brescia, Italy and ${ }^{2}$ Bone Metabolic Unit, Scientific Institute H San Raffaele, Milan, Italy
}

(Correspondence should be addressed to V Sibilia; Email Valeria.Sibilia@unimi.it)

\begin{abstract}
Objective: The present study was performed to evaluate the potential influence of the estrogen milieu in modulating the effects of GH/IGF stimulation by a GH-releasing peptide, hexarelin (HEXA), on bone metabolism and mineral density in middle-aged female rats.

Methods: HEXA was administered for 60 days $(50 \mu \mathrm{g} / \mathrm{kg}$ s.c. twice a day) to intact and ovariectomized (OVX) 11-month-old female rats and changes in bone parameters were evaluated with respect to those of the same rats under baseline conditions and with those of control rats (intact and OVX) administered isovolumetric amounts of physiological saline. Serum total alkaline phosphatase (ALP) and urinary deoxypyridinoline (Dpd) were measured before and at various times during HEXA treatment. Bone mineral content (BMC) and density of lumbar vertebrae and femoral mid-diaphyses were measured by dual energy X-ray absorptiometry before and after treatment. In all groups, serum IGF-I levels were determined before and during treatment and the GH secretory response to HEXA was assessed at the end of the experiment.

Results: In intact rats, HEXA did not modify Dpd urinary excretion, induced a trend toward an increase of serum ALP activity and significantly increased BMC $(+6.5 \%)$ and bone area $(+4.1 \%)$ only at lumbar vertebrae. In OVX rats, HEXA did not modify the OVX-induced increase in bone turnover markers (Dpd and ALP) and did not affect the OVX-induced vertebral bone loss, but significantly increased $\mathrm{BMC}(+7.2 \%)$ and bone area $(+5.3 \%)$ at femoral mid-diaphyses. HEXA significantly increased serum IGF-I levels at day 14, but not at day 60, in both intact and OVX rats, whereas the GH secretory response to HEXA was higher in the former than in the latter.

Conclusions: Overall, the present data demonstrate that chronic HEXA treatment increases BMC and bone area at lumbar vertebrae in intact rats and at femoral diaphyses in OVX rats. The different sensitivity to HEXA of the skeletal districts examined is related to the estrogen milieu and may reflect a complex interplay between estrogens and GH/IGF function.
\end{abstract}

European Journal of Endocrinology 146 855-862

\section{Introduction}

Estrogens exert regulatory actions on the human growth hormone (GH)/insulin-like growth factor (IGF-I) axis by enhancing GH secretory burst amplitude, suggesting that the interactions between GH/IGF and estrogens might be of relevance for the maintenance of bone mass at menopause. The observations that: (i) $\mathrm{GH}$ levels are positively related to estrogen levels (1); (ii) in postmenopausal women estrogen-replacement therapy increases $\mathrm{GH}$ secretion and decreases IGF-I circulating levels (2); (iii) surgically induced menopause (i.e. bilateral oophorectomy) increases serum IGF-I concentrations (3); and (iv) estrogens and GH exert synergistic actions on human osteoblast-like cells (4) fit in well with the above view and open the perspective that the normalization of the
GH/IGF-I axis should be of therapeutic benefit in patients with postmenopausal osteoporosis. However, the few studies performed so far in elderly osteoporotic women treated with GH or IGF-I have led to conflicting results and the therapeutic perspectives of GH for bone loss are still matters of debate $(5,6)$.

Among the several strategies to restore and/or enhance the GH/IGF-I axis, the use of GH secretagogues (GHSs) has drawn considerable interest. These latter compounds, i.e. synthetic, not natural, peptidyl and non-peptidyl molecules with no structural homology with GH-releasing hormone (GHRH), appear to circumvent the problems related to exogenous $\mathrm{GH}$ and/or IGF-I administration and offer the unique opportunity to reset in a physiological way the GH/IGF-I axis and then to study how estrogens and GH/IGF function interact on bone metabolism. Such studies can be 
performed in female rats because, despite speciesspecific differences in the neuroregulation of $\mathrm{GH}$ secretion (7), they are responsive to GHSs, and ovariectomized (OVX) rats, like postmenopausal women, undergo bone loss as a consequence of estrogen depletion $(8-10)$.

Along this line of reasoning, the following study was designed to assess the influence of stimulation of the GH/IGF-I axis on the adult skeleton depending upon the estrogen milieu. Hence, bone metabolism and bone mineral density (BMD) were evaluated in intact or OVX rats with normal or enhanced GH secretion ensuing from long-term administration of a GHS, hexarelin (HEXA), a peptide already tested in male rats and found effective in preventing bone loss due to androgen deficiency (11). The possible bias due to the OVXinduced enhancement of circulating IGF-I (12) and the ensuing activation of the negative IGF-I feedback on the GH response to HEXA was considered, and serum IGF-I levels were measured throughout the course of the experiments. The presence of a GH secretory response to an acute challenge with HEXA at the end of the experiment was assessed to ensure the resiliency of HEXA action to the negative GH autofeedback mechanism.

\section{Materials and methods}

\section{Experimental protocol}

Thirty-two female retired breeding Sprague-Dawley rats (Harlan, Calco, Italy), 11 months old at the beginning of the study, were used. To allow a controlled environment, all rats were kept individually at $25^{\circ} \mathrm{C}$ with a $12 \mathrm{~h}$ light: $12 \mathrm{~h}$ darkness cycle; they had freely available standard rat diet (Charles River, Calco, Italy) and water. The body weight (BW) of the rats was monitored once a week during the study. All experimental procedures were approved by the Ethic Committee of the Department of Pharmacology of the University of Milan.

This study was carried out to examine the effects of HEXA (kindly supplied by Pharmacia \& Upjohn, Stockholm, Sweden) on bone metabolism and BMD in intact or OVX rats. For this purpose, bone parameters and biochemical markers of bone turnover were monitored in the same animal at baseline and at various days of treatment.

The rats were weight matched and randomly divided into four groups of eight animals each; two groups underwent bilateral OVX under ether anesthesia; two groups remained intact. The treatment groups were the following: intact + saline, intact + HEXA, OVX + saline, OVX + HEXA. HEXA was administered s.c. at $50 \mu \mathrm{g} / \mathrm{kg}$ twice a day (b.i.d.), one injection between 0800 and $0900 \mathrm{~h}$ and the other between 1600 and $1700 \mathrm{~h}$. Control rats (intact and OVX) received isovolumetric amounts of saline solution. Treatments started immediately after OVX and lasted 60 days. The dose, timing and route of administration of HEXA were chosen based on previous studies (11). BMD measurements were evaluated at the start $\left(\mathrm{t}_{0}\right)$ and at day 60 $\left(t_{60}\right)$ of treatment. Twenty-four hour urine samples for measurements of deoxypyridinoline (Dpd), a marker of bone resorption, were collected from rats housed in metabolic cages (Techniplast; Gazzada, Varese, Italy) at $\mathrm{t}_{0}$ and at $\mathrm{t}_{14}, \mathrm{t}_{30}$ and $\mathrm{t}_{60}$ of treatment. Samples were immediately frozen and stored at $-20{ }^{\circ} \mathrm{C}$ until assayed. Blood samples for measurement of IGF-I $\left(t_{0}, t_{14}\right.$ and $\left.t_{60}\right)$ and total alkaline phosphatase (ALP) $\left(t_{0}, t_{14}, t_{30}\right.$ and $t_{60}$ ) activity, a marker of bone formation, were drawn, under light ether anesthesia, by cardiac puncture. Serum was stored at $-20^{\circ} \mathrm{C}$ until assay.

Twenty-four hours after the last administration of HEXA or saline, all rats were sampled from the retroorbital venous plexus before and $20 \mathrm{~min}$ after an acute challenge with HEXA $(50 \mu \mathrm{g} / \mathrm{kg}$ s.c.) for measurement of $\mathrm{GH}$ plasma concentrations.

\section{Assays}

Total urinary Dpd levels were measured by reversephase HPLC as previously described (13). Briefly, urine samples $(250 \mu \mathrm{l})$ were hydrolyzed in an equal volume of $12 \mathrm{~mol} / \mathrm{l} \mathrm{HCl}$ at $110^{\circ} \mathrm{C}$ overnight. Hydrolysates were applied to SPE CF-1 cellulose columns (BioRad Laboratories, Segrate, Italy) to extract the analytes. Samples were eluted with $1.5 \mathrm{ml} \mathrm{1 \%} \mathrm{hepta-}$ fluorobutyric acid. The analytes were detected fluorometrically (excitation $295 \mathrm{~nm}$, emission $400 \mathrm{~nm}$ ) utilizing their native fluorescence. The detection limit was $5 \mathrm{pmol} / \mathrm{ml}$. The interassay variation was $10.4 \%$. The total daily excretion of Dpd was corrected for creatinine excretion and expressed as nmol/l Dpd:mmol/l creatinine. Urinary creatinine was measured colorimetrically using a commercial kit (Sigma Diagnostics, Milan, Italy). Urinary Dpd samples from the same rat were measured in a single run.

Total serum ALP was determined using a commercial kit (MPR3) provided by Boehringer Mannheim, Mannheim, Germany. Inter- and intra-assay coefficient of variation $(\mathrm{CV})$ values were 3 and $3.3 \%$ respectively.

Plasma GH was measured by RIA using materials supplied by the National Institute of Arthritis, Metabolism, and Digestive Diseases, Baltimore, MD, USA (NIAMDD). Results are expressed in $\mathrm{ng} / \mathrm{ml}$ of the reference standard (NIAMDD-rat-GH-RP-2). The sensitivity of the method was $0.5 \mathrm{ng} / \mathrm{ml}$. Inter- and intra-assay CV values were 12 and $8.5 \%$ respectively. Total IGF-I concentrations were measured using a commercial kit (rat IGF-I RIA; Mediagnost, Tübingen, Germany). The detection limit of the assay was $21 \mathrm{ng} / \mathrm{ml}$.

\section{Bone mineral measurements}

All rats were anesthetized with ketamine hydrochloride (100 mg/kg, i.p.) plus xylazine $(4 \mathrm{mg} / \mathrm{kg}$, i.p.) and 
scanned by dual energy-X-ray absorptiometry (DXA) with a Hologic QDR-1000 instrument (Hologic Inc., Waltham, MA, USA) in the ultra-high resolution mode with a longitudinal line spacing of $0.254 \mathrm{~mm}$, implemented with a collimator $1.0 \mathrm{~mm}$ in diameter and with the High Resolution Software (version 4.47) analysis adapted for small animals. The femoral middiaphysis subregion and lumbar spine were scanned. The region of interest was positioned normally to the longitudinal axis of the femur in the subregion of the middle diaphysis and over four vertebrae (L1-L4). The software provided the area $\left(\mathrm{cm}^{2}\right)$, the bone mineral content $(\mathrm{BMC})(\mathrm{g})$ and the BMD $\left(\mathrm{g} / \mathrm{cm}^{2}\right)$ of the selected subregion of the femur and of the vertebrae. We selected these skeletal sites since reportedly they are the most sensitive to GH treatment (14). The reproducibility of BMD and BMC measurements by this DXA, evaluated by ten measurements, was $1 \%$ for $\mathrm{BMD}$ and 3\% for BMC (CV values).

\section{Statistical analysis}

Statistical analysis was performed with a statistical package (PRISM; GraphPad Software San Diego, CA, USA). All data are shown as means \pm S.E.M. Within each group, changes from baseline were tested by one-way repeated-measures ANOVA followed by a
Bonferroni multiple range test or by a two-tailed paired $t$-test. For comparison between groups at the same time, two-tailed unpaired $t$-tests were used.

Serum IGF-I values were expressed either as absolute values or as $t_{n} / t_{0}\left(t_{n}=\right.$ value at time $\left.n\right)$. To normalize the variation of IGF-I levels with respect to basal values, statistical analysis was performed on $t_{n} / t_{0}$. $P<0.05$ was considered significant.

\section{Results}

In intact saline- or HEXA-treated rats, no significant change in the urinary excretion of Dpd, the specific index of bone resorption, was observed throughout the experimental period. As expected, OVX caused a significant increase in the urinary excretion of Dpd by $t_{14}$, an effect which was not modified by HEXA administration (Fig. 1). For ALP activity, a marker of bone formation, no significant change with respect to baseline was observed in intact saline- or HEXA-treated rats, even though a trend toward an increase was detected in the latter. Conversely, serum ALP activity was significantly increased over baseline starting from $t_{30}$ until $t_{60}$ in saline-treated OVX rats and even earlier $\left(\mathrm{t}_{14}\right)$ in HEXA-treated OVX rats (Table 1).

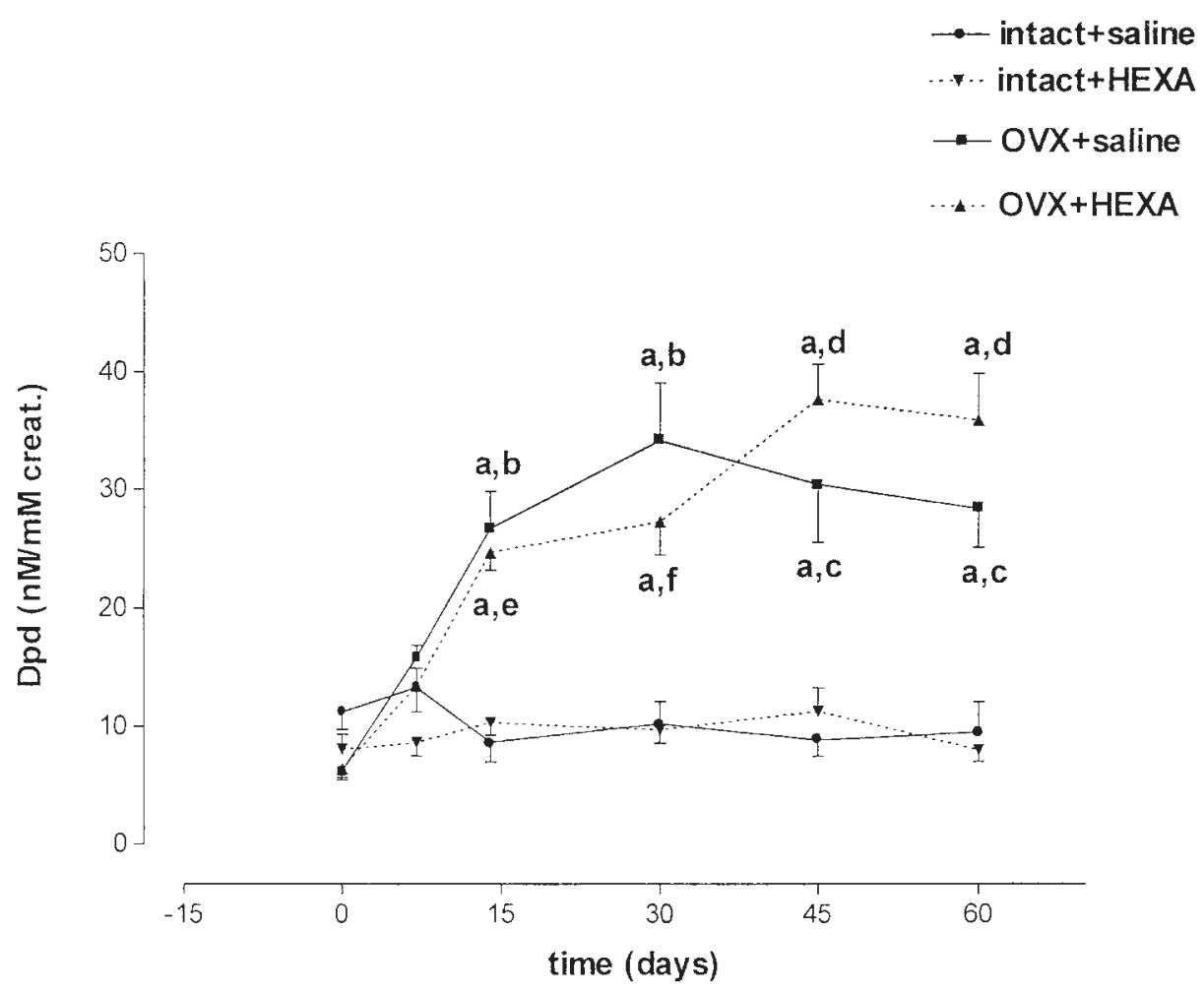

Figure 1 Effects of 60 day treatment with hexarelin (HEXA) $(50 \mu \mathrm{g} / \mathrm{kg}$ s.c., b.i.d.) on urinary excretion of deoxypyridine (Dpd) in intact and ovariectomized (OVX) rats. Means \pm S. E.M., $n=6-8$. ${ }^{a} P<0.001$ vs basal, Bonferroni test. ${ }^{b} P<0.001,{ }^{c} P<0.01$ vs intact+saline, ${ }^{\mathrm{d}} P<0.001,{ }^{\mathrm{e}} P<0.01,{ }^{\mathrm{f}} P<0.05$ vs intact + HEXA, unpaired $t$-tests. creat., creatinine. 
Table 1 Effects of 60 day treatment with HEXA (50 $\mu \mathrm{g} / \mathrm{kg}$ s.c., b.i.d.) on serum ALP activity (U/l) in intact and OVX rats at days $t_{0}, t_{14}, t_{30}$ and $t_{60}$. Data are means \pm S.E.M. of six to eight determinations.

\begin{tabular}{lcccc}
\hline Group & $\mathbf{t}_{\mathbf{0}}$ & $\mathbf{t}_{\mathbf{1 4}}$ & $\mathbf{t}_{\mathbf{3 0}}$ & $\mathbf{t}_{\mathbf{6 0}}$ \\
\hline Intact + saline & $60.9 \pm 5.5$ & $69.3 \pm 7.5$ & $62.8 \pm 3.4$ & $61.4 \pm 5$ \\
Intact + HEXA & $85.1 \pm 3.7$ & $90.4 \pm 6.0$ & $96.7 \pm 8.8$ & $113.9 \pm 9.9$ \\
OVX + saline & $72.3 \pm 6.2$ & $104.2 \pm 8.6$ & $113.9 \pm 9.4^{*}$ & $114.5 \pm 12.0^{*}$ \\
OVX + HEXA & $62.5 \pm 7.4$ & $99.3 \pm 6.1^{\star *}$ & $103.3 \pm 5.8^{* * *}$ & $98.9 \pm 6.3^{\star *}$ \\
\hline${ }^{*} P<0.05^{* *} P<0.01^{* * *} P<0.001$ & & &
\end{tabular}

Throughout the experiment, vertebral (Table 2) and femoral mid-diaphysis BMD values (Table 3) remained unchanged in intact saline- and HEXA-treated rats. At the end of the experiments, however, the intact HEXA-treated group showed an increase in BMC and bone area at lumbar vertebrae and femoral middiaphyses, which reached significance from baseline only in the former site (Table 2).

In saline-treated rats, OVX caused a significant decrease in both vertebral BMC $(-10.9 \%)$ and BMD $(-5.3 \%)$ values (Table 2$)$, whereas no BMC or BMD changes were detected in the femoral mid-diaphyses (Table 3). Treatment with HEXA did not influence the OVX-induced vertebral bone loss (Table 2), in that the percentage of $\mathrm{BMC}(-7.3 \%)$ and BMD $(-6.3 \%)$ decrease was not significantly different from those detected in saline-treated OVX rats. HEXA induced a significant increase in BMC and bone area at the femoral mid-diaphysis (Table 3).

The GH response to an acute challenge with HEXA in all rats after 60 days of treatment is shown in Fig. 2. Since overall baseline GH levels $24 \mathrm{~h}$ after the last administration of HEXA were not different from those of saline-injected rats, data were pooled in a single group in both intact and OVX rats. Acute HEXA administration significantly increased GH secretion in all the experimental groups, and in intact rats pretreated with HEXA the GH stimulatory activity of acute administration of the peptide was significantly higher than that of saline-treated rats. In addition, the magnitude of the GH response to the peptide was different depending upon the estrogen milieu. Hence, after the acute
HEXA challenge the GH response in OVX rats was significantly lower than that of intact rats.

In intact rats, HEXA administration induced a significant increase in serum IGF-I levels at $t_{14}$, and thereafter, IGF-I levels returned to baseline. OVX significantly increased IGF-I levels starting from $t_{14}$ and until $t_{60}$ days. The OVX-induced elevation in serum IGF-I levels was significantly magnified by chronic HEXA treatment on $\mathrm{t}_{14}$, although at the end of treatment circulating IGF-I levels in HEXA-treated OVX rats were comparable with those of saline-treated OVX rats (Fig. 3).

The mean BW of all rats at the beginning of the experiment was $311 \pm 4 \mathrm{~g}$. HEXA, despite its GH-releasing activity, did not influence BW, no difference in the final weight being detected in intact HEXA-treated $(326 \pm 9 \mathrm{~g})$ vs saline-treated $(331 \pm 15 \mathrm{~g})$ rats. This is probably due to the fact that the growth of these middle-aged rats had plateaud. Estrogen deficiency resulted in a significant $(P<0.01)$ weight increment with respect to baseline value in saline-treated OVX

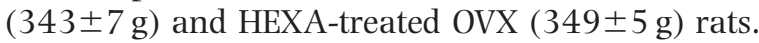

\section{Discussion}

The present study shows that the estrogen environment modulates the bone effects of HEXA. In intact rats, HEXA caused a significant increase in BMC $(+6.5 \%)$ and bone area $(+4.1 \%)$ at lumbar vertebrae and a smaller increase of the same parameters at the femoral diaphyseal site investigated. Under a state of estrogen

Table 2 Effects of 60 day treatment with HEXA (50 $\mu \mathrm{g} / \mathrm{kg}$ s.c., b.i.d.) on bone mineral content (BMC), bone area and bone mineral density (BMD) in the lumbar vertebrae of intact and OVX rats. Data are means \pm S.E.M. of six to eight determinations.

\begin{tabular}{lcccc}
\hline Group & $\begin{array}{c}\text { Time } \\
(\text { days })\end{array}$ & $\begin{array}{c}\text { BMC } \\
(\mathrm{g})\end{array}$ & $\begin{array}{c}\text { Area } \\
\left(\mathrm{cm}^{2}\right)\end{array}$ & $\begin{array}{c}\text { BMD } \\
\left(\mathrm{g} / \mathrm{cm}^{2}\right)\end{array}$ \\
\hline Intact + saline & $\mathrm{t}_{0}$ & $0.4734 \pm 0.01$ & $2.067 \pm 0.04$ & $0.2288 \pm 0.006$ \\
& $\mathrm{t}_{60}$ & $0.4724 \pm 0.02$ & $2.050 \pm 0.06$ & $0.2301 \pm 0.008$ \\
Intact + HEXA & $\mathrm{t}_{0}$ & $0.4910 \pm 0.01$ & $2.058 \pm 0.04$ & $0.2414 \pm 0.003$ \\
& $\mathrm{t}_{60}$ & $0.5229 \pm 0.01^{\star *}$ & $2.142 \pm 0.07^{*}$ & $0.2435 \pm 0.003$ \\
OVX + saline & $\mathrm{t}_{0}$ & $0.4881 \pm 0.02$ & $2.042 \pm 0.04$ & $0.2383 \pm 0.006$ \\
& $\mathrm{t}_{60}$ & $0.4349 \pm 0.03^{*}$ & $2.012 \pm 0.05$ & $0.2257 \pm 0.006^{\star *}$ \\
OVX + HEXA & $\mathrm{t}_{0}$ & $0.4989 \pm 0.01$ & $2.070 \pm 0.03$ & $0.2408 \pm 0.004$ \\
& $\mathrm{t}_{60}$ & $0.4627 \pm 0.01^{*}$ & $2.048 \pm 0.02$ & $0.2257 \pm 0.005^{\star * *}$ \\
\hline
\end{tabular}

${ }^{\star} P<0.05,{ }^{\star \star} P<0.01,{ }^{\star * \star} P<0.001$ vs $\mathrm{t}_{0}$, paired $t$-test. 
Table 3 Effects of 60 day treatment with HEXA ( $50 \mu \mathrm{g} / \mathrm{kg}$ s.c., b.i.d.) on BMC, bone area and BMD in the central subregion of the femoral diaphyses of intact and OVX rats. Data are means \pm S.E.M. of six to eight determinations.

\begin{tabular}{lcccc}
\hline Group & $\begin{array}{c}\text { Time } \\
\text { (days) }\end{array}$ & $\begin{array}{c}\text { BMC } \\
(\mathrm{g})\end{array}$ & $\begin{array}{c}\text { Area } \\
\left(\mathrm{cm}^{2}\right)\end{array}$ & $\begin{array}{c}\text { BMD } \\
\left(\mathrm{g} / \mathrm{cm}^{2}\right)\end{array}$ \\
\hline Intact + saline & $\mathrm{t}_{0}$ & $0.0473 \pm 0.006$ & $0.1551 \pm 0.003$ & $0.3057 \pm 0.004$ \\
& $\mathrm{t}_{60}$ & $0.0479 \pm 0.001$ & $0.1548 \pm 0.003$ & $0.3098 \pm 0.005$ \\
Intact + HEXA & $\mathrm{t}_{0}$ & $0.0412 \pm 0.002$ & $0.1358 \pm 0.005$ & $0.3024 \pm 0.004$ \\
& $\mathrm{t}_{60}$ & $0.0420 \pm 0.002$ & $0.1385 \pm 0.004$ & $0.3022 \pm 0.006$ \\
OVX + saline & $\mathrm{t}_{0}$ & $0.0447 \pm 0.001$ & $0.1546 \pm 0.003$ & $0.2924 \pm 0.005$ \\
& $\mathrm{t}_{60}$ & $0.0448 \pm 0.001$ & $0.1542 \pm 0.002$ & $0.2836 \pm 0.007$ \\
OVX + HEXA & $\mathrm{t}_{0}$ & $0.0427 \pm 0.001$ & $0.1458 \pm 0.002$ & $0.3009 \pm 0.006$ \\
& $\mathrm{t}_{60}$ & $0.0458 \pm 0.001^{*}$ & $0.1535 \pm 0.002^{*}$ & $0.2978 \pm 0.005$ \\
\hline
\end{tabular}

${ }^{\star} P<0.05$ vs $\mathrm{t}_{0}$, paired $t$-test.

deficiency, sustained HEXA treatment did not affect the OVX-induced bone loss at the lumbar vertebrae whereas it significantly increased BMC $(+7.2 \%)$ and bone area $(+5.3 \%)$ at the femoral diaphysis. In either condition, the parallel increase in BMC and bone area caused by HEXA can account for the unchanged BMD values.

In saline-treated intact rats, both DXA parameters did not change throughout the experiments at either skeletal site examined; this implies that in HEXAtreated rats the observed increase in BMC and bone area was actually due to administration of the peptide. In keeping with this finding, long-term administration of ipamorelin and GHRP-6, two other GHSs, induced an increment of lumbar BMC in young intact female rats (15).

The finding that HEXA, besides GH, significantly increased serum IGF-I levels raises the possibility that the detected increase in BMC could be due to the known bone-promoting activity of both GH and IGF-I. Indeed, it has been reported that in intact female rats

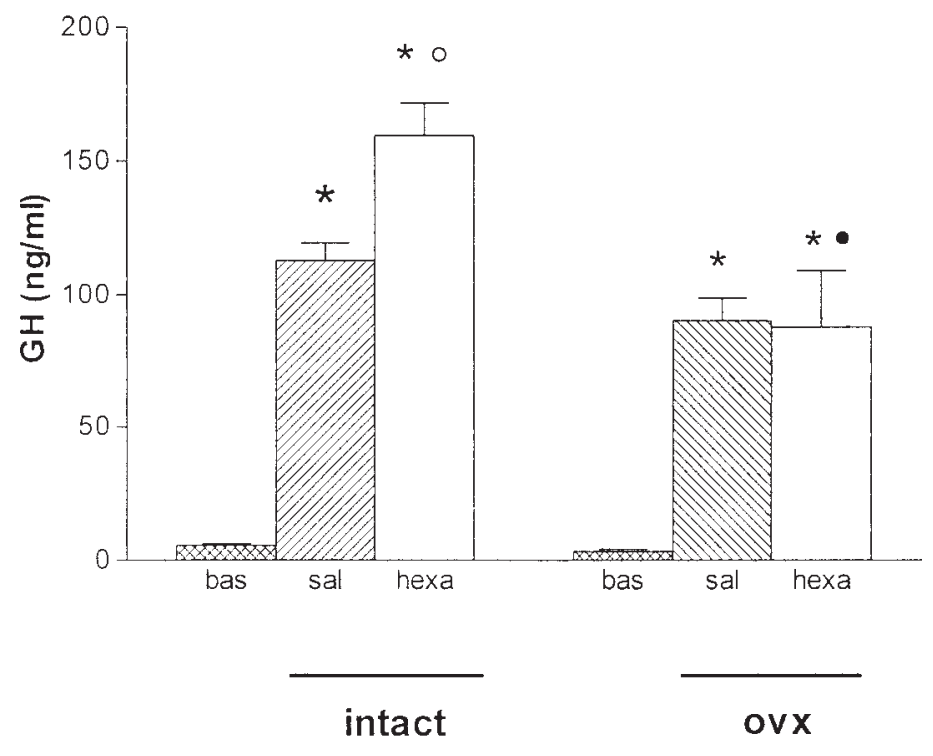

Figure 2 Peak GH response (means \pm S.E.M., $n=6-8$ ) at $20 \mathrm{~min}$ after an acute challenge with HEXA $(50 \mu \mathrm{g} / \mathrm{kg} \mathrm{s.c.)}$ in intact or OVX rats pretreated for 60 days with saline (sal) or HEXA. Bas = basal GH values measured before HEXA challenge in both groups. ${ }^{*} P<0.001$ vs basal, Bonferroni test. ${ }^{\circ} P<0.05$ vs intact + saline, ${ }^{\bullet} P<0.05$ vs intact + HEXA, unpaired $t$-tests. 


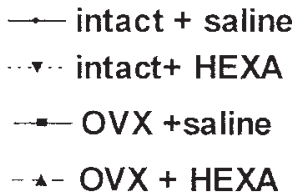

$\rightarrow-$ OVX + HEXA
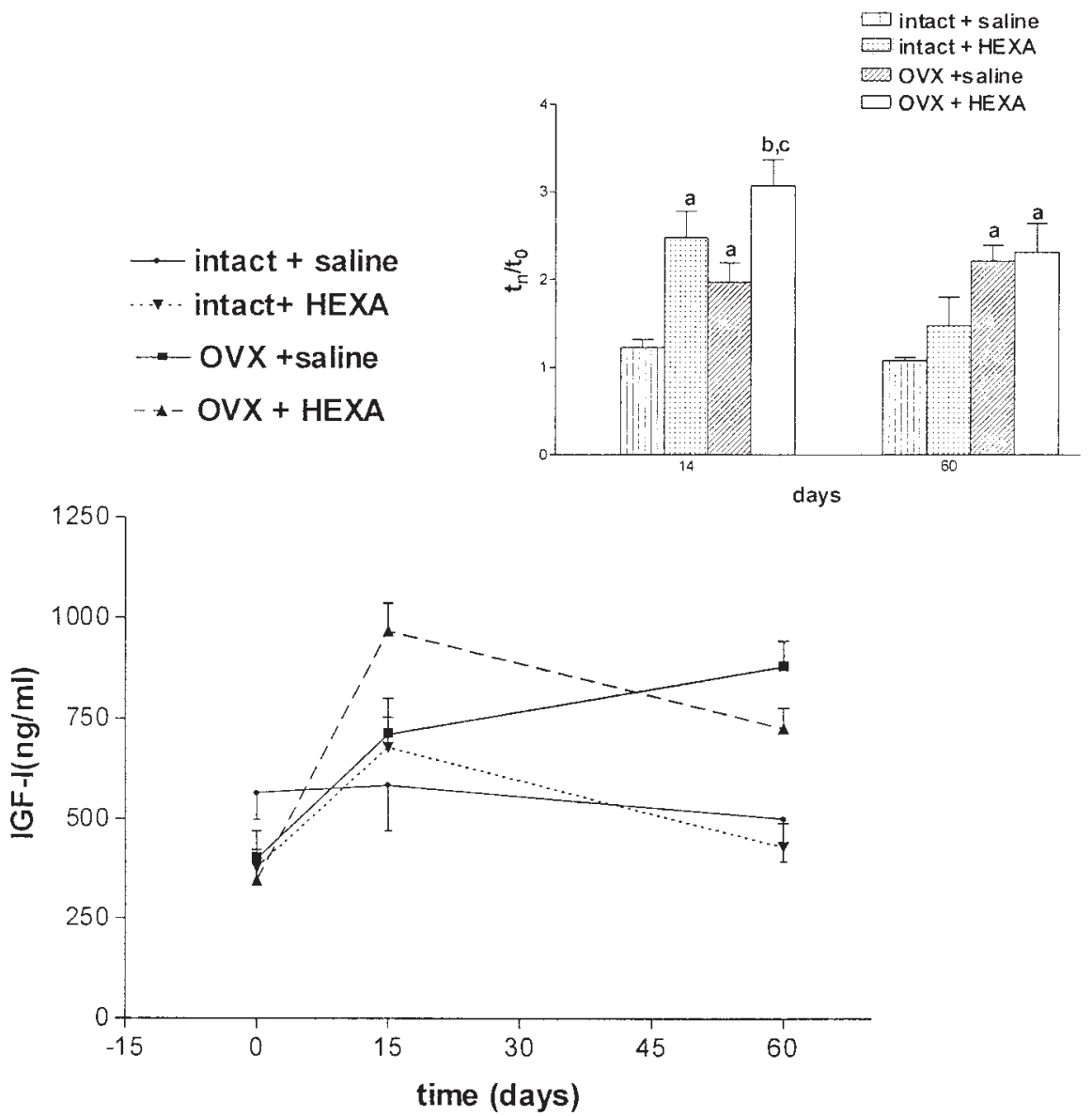

Figure 3 Effects of 60 day treatment with HEXA (50 $\mathrm{g} / \mathrm{kg}$ s.c., b.i.d.) on total serum IGF-I levels in intact and OVX rats. Inset shows statistical analyses performed on $\mathrm{t}_{\mathrm{n}} / \mathrm{t}_{0}$ as described in Materials and methods. ${ }^{\mathrm{a}} P<0.05,{ }^{\mathrm{b}} P<0.01 \mathrm{vs}$ intact + saline; ${ }^{\mathrm{c}} P<0.05$ vs OVX + saline, Bonferroni test.

units, could have amplified the positive effect observed with HEXA at lumbar vertebrae.

Our biochemical data, however, are not consistent with the view that the increase in GH/IGF-I ensuing from HEXA administration exerted a positive influence on bone balance at the remodeling level. In fact, urinary Dpd excretion, an index of bone resorption, did not change in the intact rats following HEXA treatment.

It is likely that the observed increase in BMC and bone area detected in HEXA-treated rats might be due to activation of the modeling process via an enhanced bone apposition rate at the periosteal surface. The gradual increase in ALP activity induced by HEXA and the difference between the ALP changes in the HEXA-treated vs control rats $(+38 \%$ vs $+1 \%$ respectively) at the end of the experiments would support this view. Accordingly, in a previous clinical study, the GHS MK677 induced a gradual, sustained increase of bone formation markers (22). In contrast to the present study, in a previous report we found HEXA ineffective in old dogs in modifying ALP activity (23).
Histomorphometric analyses are therefore mandatory before an effect of HEXA on the periosteal envelope can be unequivocally established.

A number of in vivo and in vitro findings bespeak a complex regulatory action of estrogens on circulating GH/IGF-I levels as well as on bone. Estradiol sensitizes the pituitary to GHRH (24), and in adulthood, by inhibiting the hepatic synthesis of IGF-I, impairs the negative feedback regulation of $\mathrm{GH}$ release (25). Accordingly, estrogens increase GH responses to various GH-releasing stimuli in rats and in postmenopausal women $(26,27)$. Opposite changes are reported in estrogen deficiency; in fact, the GH-releasing activity of HEXA is reduced in postmenopausal women (28). It is possible that the increase in serum IGF-I levels detected during estrogen deficiency could account for the decreased GH stimulatory effect of HEXA in OVX rats. Therefore, a likely explanation for the lack of response to HEXA of OVX rats at the lumbar spine is that the amount of GH that the peptide could release was too small to counteract the bone loss induced by OVX. In this context, it is worth noting that only 
high doses of $\mathrm{GH}$ have been reported to reverse the OVX-induced bone loss at vertebral sites $(14,29)$. Furthermore, in mice too, the lack of estrogen, besides a negative influence on $\mathrm{GH}$ secretion, reduces the boneprotective effect of $\mathrm{GH}(30)$.

In contrast, the positive effect of HEXA on diaphyseal BMC might reflect the higher sensitivity to the GH/IGF system of cortical bone sites (14). Inferential support to this view also derives from the observation that, in aged OVX rats, GH or IGF-I, reportedly, did not influence any biochemical or morphometric parameter of trabecular bone remodeling, but did increase femoral diaphyseal cortical bone (31). Moreover, in adult OVX rats IGF-I increased the BMD at the tibial diaphysis but not at the lumbar vertebrae (32).

Another important mechanism contributing to the increased sensitivity of cortical femoral bone to HEXA when ovarian hormones are lacking may rest on a synergistic interaction between GH/IGF and mechanical stimuli. Since OVX induced a significant increase in BW, and the femur more than the spine is exposed to weight-bearing stress, it might be surmised that an increase in mechanical loading had amplified the bone anabolic effects of GH/IGF at femoral diaphyseal sites. In this context, Yeh et al. (33) have found a positive interaction of exercise and a low GH dose on cortical surfaces of the tibia and a negative interaction in vertebrae.

It is noteworthy that the skeletal effects of HEXA herein detected in female rats were different from those previously observed in male rats (11). In contrast to females, in orchidectomized males HEXA prevented the decrease in vertebral BMD and the increase in the urinary excretion of bone resorption markers. The complex estrogen-GH/IGF interactions discussed above and the sex-related difference in the $\mathrm{GH}$ secretory response to HEXA (male $>$ female) in rats (34) might explain the gender difference detected in the bone response to HEXA (11, and this study). Interestingly, also in humans, the bone effects of GH-replacement therapy have been reported to display a similar gender difference (35).

In summary, the present data indicate that the effect of a GHS on bone is estrogen-dependent. To optimize the anabolic action on bone of estrogen-replacement therapy, further research is needed to characterize the complex interactions between estrogens and the stimulation of GH/IGF function. Hopefully, such studies will also help clarifying the potential benefit of combining a GH-releasing molecule with estrogens to counteract postmenopausal bone loss.

\section{Acknowledgements}

This work was supported by funds from the Italian MURST (40\%), Rome. We would like to thank the NIAMDD for their kind supply of the GH kit and
Pharmacia-Upjohn (Stockholm, Sweden) for providing HEXA.

\section{References}

1 Ho KY. Secretory patterns of growth hormone according to sex and age. Hormone Research 199033 (Suppl 4) 7-11.

2 Friend KE, Hartman ML, Pezzoli SS, Clasey JL \& Thorner MO. Both oral and transdermal estrogen increase growth hormone release in postmenopausal women - a clinical research center study. Journal of Clinical Endocrinology and Metabolism $1996 \mathbf{8 1}$ $2250-2256$

3 Zofkova I \& Kancheva RL. Effect of estrogen status on bone regulating hormones. Bone $199619227-232$.

4 Slootweg MC, Swolin D, Netelenbos JC, Isaksson OG \& Onlsson C. Estrogen enhances growth hormone receptor expression and growth hormone action in rat osteosarcoma cells and human osteoblast-like cells. Journal of Endocrinology 1997155 159-164.

5 Rosen CJ \& Bilezikian JP. Anabolic therapy for osteoporosis. Journal of Clinical Endocrinology and Metabolism $2001 \mathbf{8 6}$ 957-964.

6 Sartorio A, Ortolani S, Conti A, Cherubini R, Galbiati E \& Faglia G. Effects of recombinant growth hormone $(\mathrm{GH})$ treatment on bone mineral density and body composition in adults with childhood onset growth hormone deficiency. Journal of Endocrinological Investigation $1996 \mathbf{1 9} 524-529$.

7 Muller EE, Locatelli V \& Cocchi D. Neuroendocrine control of growth hormone secretion. Physiological Reviews $1999 \mathbf{7 9}$ 511-607.

8 Aiken JM, Armstrong B \& Anderson JB. Osteoporosis after oophorectomy in the mature female rat and effect of estrogen or progestrogen replacement therapy in its prevention. Journal of Endocrinology $19725579-87$.

9 Wronski TJ, Lowry PL, Walsh CC \& Ignaszewski LA. Skeletal alterations in ovariectomized rats. Calcified Tissue International $198537324-328$.

10 Kalu DN. The ovariectomized rat model of postmenopausal bone loss. Bone and Mineral 199115 175-191.

11 Sibilia V, Cocchi D, Pagani F, Lattuada N, Moro GL, Pecile A et al. Hexarelin, a growth hormone-releasing peptide, counteracts bone loss in gonadectomized rats. Growth Hormone \& IGF Research $19999219-227$.

12 Kalu DN, Arjmandi BH, Liu CC, Salih MA \& Birnbaum RS. Effects of ovariectomy and estrogen on the serum levels of insulin-like growth factor-I and insulin-like growth factor binding protein-3. Bone and Mineral 199425 134-148.

13 Black D, Farquharson C \& Robins P. Excretion of pyridinium crosslinks of collagen in ovariectomized rats as urinary markers for increased bone resorption. Calcified Tissue International $19894 \mathbf{4}$ $343-347$.

14 Mosekilde L, Thomsen JS, Orhii PB \& Kalu DN. Growth hormone increases vertebral and femoral bone strength in osteopenic, ovariectomized, aged rats in a dose-dependent and site specific manner. Bone 199823 343-352.

15 Svensson J, Lall S, Dickson SL, Bengtsson BA, Romer J, AhnfeltRonne I et al. The GH secretagogues ipamorelin and GH-releasing peptide- 6 increase bone mineral content in adult female rats. Journal of Endocrinology 2000165 569-577.

16 Andreassen TT, Jorgensen PH, Flyvbjerg A, Orskov H \& Oxlund H. Growth hormone stimulates bone formation and strength of cortical bone in aged rats. Journal of Bone and Mineral Research 1995 10 1057-1067.

17 Andreassen TT, Melsen F \& Oxlund H. The influence of growth hormone on cancellous and cortical bone of the vertebral body in aged rats. Journal of Bone and Mineral Research $1996 \mathbf{1 1}$ $1094-1102$.

18 Ernst M \& Rodan GA. Increased activity of insulin-like growth factor (IGF) in osteoblastic cells in the presence of growth hormone $(\mathrm{GH})$ : positive correlation with the presence of the 
GH-induced IGF-binding protein BP-3. Endocrinology 1990127 $807-814$.

19 Turner RT, Colvard DS \& Spelsberg TC. Estrogen inhibition of periosteal bone formation in rat long bones: down regulation of gene expression for bone matrix proteins. Endocrinology 1990 127 1346-1351.

20 Turner RT, Riggs BL \& Spelsberg TC. Skeletal effects of estrogen. Endocrine Reviews 199415 275-300.

21 Parfitt AM. Growth hormone and adult bone remodeling. Clinical Endocrinology 199135 467-470.

22 Svensson J, Ohlsson C, Jansson JO, Murphy G, Wyss D, Krupa D et al. Treatment with the oral growth hormone segretagogue MK-677 increases markers of bone formation and bone resorption in obese young males. Journal of Bone and Mineral Research $1998131158-1166$.

23 Cella SG, Cerri CG, Daniel S, Sibilia V, Rigamonti A, Cattaneo L et al. Sixteen weeks of hexarelin therapy in aged dogs: effects on somatotropic axis, muscle morphology, and bone metabolism. Journal of Gerontology: Biological Sciences $1996 \mathbf{5 1} 439-447$.

24 Wilson ME. Regulation of the growth hormone-insulin-like growth factor I axis in developing and adult monkeys is affected by estradiol replacement and supplementation with insulin-like growth factor I. Journal of Clinical Endocrinology and Metabolism $1998832018-2028$.

25 Lieberman SA, Mitchell AM, Marcus R, Hintz RL \& Hoffman AR. The insulin-like growth factor I generation test: resistance to growth hormone with aging and estrogen replacement therapy. Hormone and Metabolism Research 199426 229-233.

26 Mallo F, Alvarez CV, Benitez L, Burgera B, Coya R, Casanueva F et al. Regulation of His-DTrp-Ala-Trp-DPhe-Lys- $\mathrm{NH}_{2}$ (GHRP-6)induced GH secretion in the rat. Neuroendocrinology $1993 \mathbf{5 7}$ 247-256.

27 Shan N, Evans WS, Bowers CY \& Veldhuis JD. Oral estradiol administration modulates continuos intravenous growth hormone (GH)-releasing peptide-2-driven $\mathrm{GH}$ secretion in postmenopausal women. Journal of Clinical Endocrinology and Metabolism $2000852649-2659$.
28 Arvat E, Gianotti L, Broglio F, Maccagno B, Bertagna A, Deghenghi $\mathrm{R}$ et al. Oestrogen replacement does not restore the reduced GH-releasing activity of hexarelin, a synthetic hexapeptide, in post-menopausal women. European Journal of Endocrinology $1997136483-487$.

29 Eschen C \& Andreassen TT. Growth hormone normalizes vertebral strength in ovariectomized rats. Calcified Tissue International $1995 \mathbf{5 7} 392-396$.

30 Sandstedt J, Tornell J, Norjavaara E, Isaksson OGP \& Ohlsson C. Elevated levels of growth hormone increase bone mineral content in normal young mice, but not in ovariectomized mice. Endocrinology $19961373368-3374$.

31 Verhaeghe J, Van Bree R, Van Herck E, Thomas H, Skottner A, Dequeker J et al. Effects of recombinant human growth hormone and insulin-like growth factor-I with or without $17 \beta$-estradiol, on bone and mineral homeostasis of aged ovariectomized rats. Journal of Bone and Mineral Research 199611 1723-1735.

32 Tobias JH, Chow JWM \& Chambers TJ. Opposite effects of insulinlike growth factor-I on the formation of trabecular and cortical bone in adult female rats. Endocrinology $19921312387-2392$.

33 Yeh JK, Aloia JF \& Chen M. Growth hormone administration potentiates the effect of treadmill exercise on long bone formation but not on vertebrae in middle aged rats. Calcified Tissue International $1994 \mathbf{5 4} 38-43$.

34 Sibilia V, Cocchi D, Pagani F, Pecile A \& Netti C. The influence of sex and gonadectomy on the growth hormone and corticosterone response to hexarelin in the rat. Life Sciences $200068321-329$.

35 Johansson AG. Gender difference in growth hormone response in adults. Journal of Endocrinological Investigation 199922 (Suppl 5) $58-60$.

Received 26 October 2001

Accepted 20 February 2002 